\title{
Electric Arc Furnace Voltage Flicker Mitigation by Applying a Predic- tive Method with Closed Loop Control of the TCR/FC Compensator
}

\author{
Arash Kiyoumarsi ${ }^{\dagger}$, Mohhamad Ataei, Rahmatollah Hooshmand* \\ and Arash Dehestani Kolagar*
}

\begin{abstract}
Modeling of the three phase electric arc furnace and its voltage flicker mitigation are the purposes of this paper. For modeling of the electric arc furnace, at first, the arc is modeled by using current-voltage characteristic of a real arc. Then, the arc random characteristic has been taken into account by modulating the ac voltage via a band limited white noise. The electric arc furnace compensation with static VAr compensator, Thyristor Controlled Reactor combined with a Fixed Capacitor bank (TCR/FC), is discussed for closed loop control of the compensator. Instantaneous flicker sensation curves, before and after accomplishing compensation, are measured based on IEC standard. A new method for controlling TCR/FC compensator is proposed. This method is based on applying a predictive approach with closed loop control of the TCR/FC. In this method, by using the previous samples of the load reactive power, the future values of the load reactive power are predicted in order to consider the time delay in the compensator control. Also, in closed loop control, two different approaches are considered. The former is based on voltage regulation at the point of common coupling (PCC) and the later is based on enhancement of power factor at PCC. Finally, in order to show the effectiveness of the proposed methodology, the simulation results are provided.
\end{abstract}

Keywords: Electric Arc Furnace (EAF), Reactive Power Compensation

\section{Introduction}

Electric arc furnaces (EAFs) are the largest concentrated loads in the power systems. Considering the fast and extensive variations of active and reactive power, EAFs bus voltage is unbalanced and severely oscillatory. If the supply system of the furnace is not strong enough, static VAr compensators can be used for voltage stabilization and reactive power compensation at furnace bus.

The most important problems about EAF operation are voltage flicker propagation, harmonic injection and severe unbalances between phases. Because of the random motion of the electric arc, just as arc length varies during melting process, severe oscillation in supply circuit is occurred. When the frequency of this variation is bounded in the range of $1-30 \mathrm{~Hz}$, flicker can occur. In addition, because of the interaction of time delay in arc creation and the arc severe nonlinear v-i characteristic, harmonics and interharmonics can be created. Nonlinear, time-variant and random nature of EAFs operation beside high electric energy consumption of these loads, motivate the researchers to pay special attention to analyze these loads. Some of these recently performed researches are mentioned in the next paragraph.

In 1998, J. Jatskevich et al. [1] worked on adaptive VAr

\footnotetext{
$\dagger$ Corresponding Author: Department of Electrical Engineering, Faculty of Engineering, University of Isfahan, Isfahan, Iran

(kiyoumarsi@eng.ui.ac.ir, kiyoumarsi_arash@yahoo.com)

* Department of Electrical Engineering, Faculty of Engineering, University of Isfahan, Isfahan, Iran

Received : December 2, 2008; Accepted : February 1, 2010
}

compensator (AVC) which was installed to reduce flicker. The model also includes a simulation of the UIE/IEC flicker meter to determine the effectiveness of the AVC in an objective manner. In 2000, A. Garcia-Cerrada et al. [2] worked on performance of the Thyristor-controlled reactors in comparison with shunt-connected PWM voltage source inverter (PWM-VSI) for compensation of flicker caused by electric arc furnaces. An improved measuring procedure was suggested to enhance TCR performance that achieves faster compensation than traditional methods. In 2003, A. Hernandez et al. [3] evaluated flicker magnitudes of rapidly varying loads by means of a new frequency domain method and analytical expressions of the instantaneous flicker sensation were obtained in terms of inter-harmonic voltages and in 2005, S. Prins et al. [4] presented a solution in order to obtain an optimum flicker reduction at a comparatively low capacity compensator power rating by an anti-windup extension of the controller.

In this paper in order to use the measured arc voltages and currents-to describe the arc electrical behavior-a practical model of EAF based on random variables is proposed. Then, voltage flicker that appears from EAF's operation is compensated using static VAr compensator. A method for $\mathrm{TCR} / \mathrm{FC}$ control is also suggested. This proposed method is based on applying a predictive method beside the TCR/FC closed-loop control. Although, this new approach is not completely able to compensate the flicker intensity, it can suppress flicker level much better than conventional methods.

At a detailed glance, section 2 commences to explain the electric arc furnace operation and its electrical characteristics. A model for EAF is used which is able to minimize 
error compared with actual arc voltage-current characteristics. Different operating stages of EAF such as scrap, melting and refining can be considered via this model in simulations. Section 3 introduces the description of the flicker, the flicker-meter and the results of instantaneous flicker sensation curves and their corresponding cumulative probability function (CPF) curves for several time instances. In a glimpse, the results of instantaneous flicker level (IFL) and CPF for the closed-loop control of the TCR/FC compensator using voltage regulator approach and obtained results are compared for the EAF according to the one obtained before compensation in section 4 . The results for another closed-loop control of the TCR/FC compensator based on power factor enhancement are presented in section 5. In this section, at first, power factor in polluted systems is briefly studied and based on previously-defined equations and related relations, power factor at PCC, in which both harmonics and unbalances are present, reactive power compensation is successfully carried out. Section 6 contains the application of a predictive method to compensate the delay time in SVC. Using this prediction approach, considering the previous and present values of the load reactive power, its future values will be predicted. Then, issues related to predictive closed-loop of TCR/FC for the EAF are discussed and addressed at the end of paper, i.e. in sections 7 and 8 . In these two sections the obtained IFL and $\mathrm{CPF}$ curves for the closed-loop control and their predictive form based on voltage regulation at PCC are studied. Finally, the predictive closed-loop control of TCR/FC, which its operation is based on power factor enhancement, is included in section 9. The paper ends with a few conclusions, several suggestions to commence to the new researches on these closed-loop methods in section 10 .

\section{EAF Modeling}

EAFs are often used to melt and to refine metals. Due to recently-developed numerous applications of EAF in metal industry; they affect seriously power quality problems and cause them to be rapidly increased. Therefore, one of the most important sources of harmonic generation, voltage flicker and unbalance in power networks are EAFs. To find methods to reduce these destructive effects, the impression of these nonlinear and time varying loads on power quality indexes in all over the power system should be evaluated. Therefore, knowing time domain response of an EAF for this evaluation is very important. On the other hand, having an exact and practical model of an EAF that explains unpredictable, non periodic and nonlinear behavior of an electric arc is necessary. Fig. 1 shows equivalent circuit of a balanced EAF.

Different models for EAF are previously proposed. Although these models can represent the arc phenomenon behavior, to evaluate the problem more exactly, these models do not cover some properties of the arc such as random operation characteristic. Furthermore, these models propose a mathematical deterministic equation for arc $\mathrm{v}-\mathrm{i}$ characteristic.

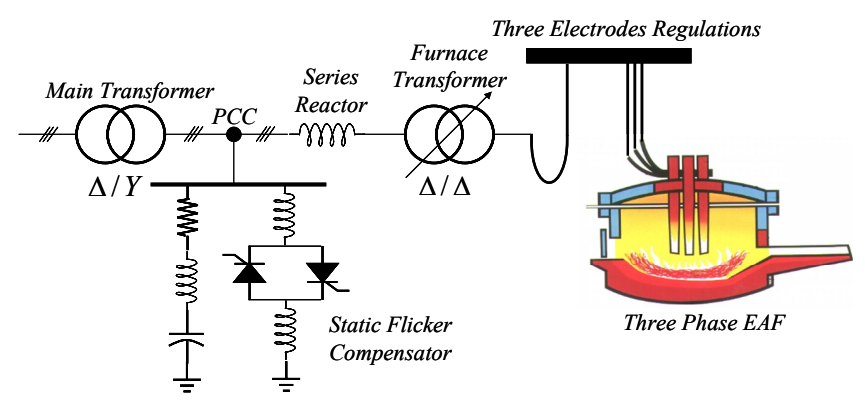

Fig. 1. Single line diagram of the EAF equivalent circuit.

In this paper, we try to propose a method to model EAFs that contains random behavior of the arc and has minimum error compared with actual arc model. This means that for a special EAF, by sampling arc current in each stage of EAF operation such as scrap, melting and refining, we obtain the arc model. Thus, after sampling ac current in each stage of furnace operation, applying a program, arc is modeled as a current controlled voltage source. Corresponding to the input current that is the arc current, arc voltage is obtained by interpolating based on previous samples. According to random behavior of the arc and the fact that in this paper we want to lay stress on this property, in order to model arc random nature, a band limited white noise based on existing frequency band in flicker, is generated and obtained voltage is modulated by the white noise [5]. The preference of this model to the others is that this model is based on actual samples obtained from EAF. Therefore, this model has a behavior close to the actual arc. Simulation results for arc model, with including flicker noise, are shown in Fig. 2.

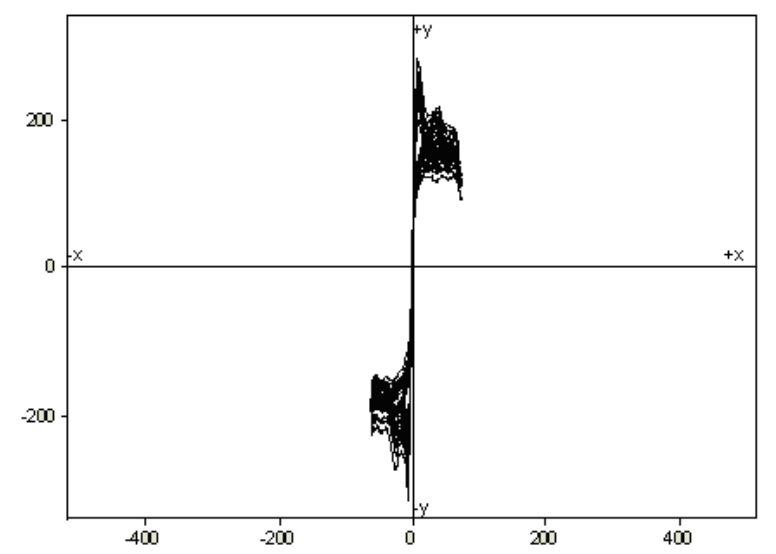

Fig. 2. V-I characteristic of the electric arc, considering flicker: $\mathrm{X}$-axis shows current in $\mathrm{kA}$ and $\mathrm{Y}$-axis shows voltage in $\mathrm{V}$.

\section{Voltage Flicker and Its Measurement}

\subsection{Description of Voltage Flicker Phenomenon}

Participators of electric industry generally expect a high quality voltage source from generation companies. But 
because of some reasons, fluctuations and distortions may be occurred in their supply voltage and cause customer dissatisfaction or production of some fatal effects on their equipment. Therefore, voltage fluctuation evaluation problem, the ways of its mitigation and power quality improvement are considered from generation companies' point of view. Sudden variation in equipment current loads such as electric arc furnace, rolling systems, excavation and welding systems and starting current of electric motors can cause voltage flicker in power networks. Voltage fluctuation effects can be seen in decreasing and increasing the intensity of light of the lamps and also flight in TV images and effects on hospital systems.

\subsection{Principles of IEC Flicker Meter}

IEC flicker meter simulates spectator reaction independent of flicker source [6], [7]. In fact because the flicker meter operates based on flicker distinction feeling, measurement of flicker is relative. The basis of flicker calculation by IEC flicker meter is that flicker intensity in input waveform is considered according to the quantity proper with flicker intensity [6], [9]. In this manner the value of the corresponding quantity shows existing flicker indicator at each moment in input signal and also is an indication of the intensity and weakness of the flicker. The name of this quantity is IFL. The IFL is an indication of instantaneous flicker value in each moment [8], [10]. Fig. 3 shows the block diagram of the IEC flicker meter.

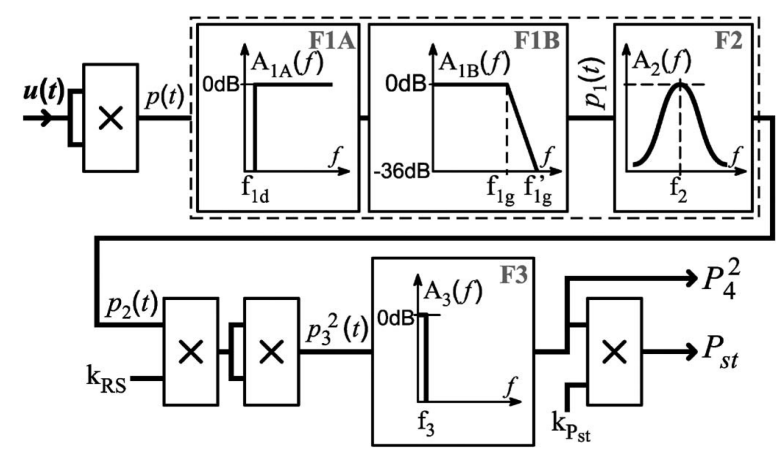

Fig. 3. IEC Flicker-meter block diagram [11].

\subsection{Description of the Flicker-meter Blocks [6-12]}

\section{Block 1: Input Voltage Adaptor}

This block contains a signal generator for controlling of the flicker-meter calibration and voltage adaptor circuit that scales the input RMS voltage to a suitable level for internal reference level.

\section{Block 2: Squaring Demodulator}

The purpose of this block is to simulate the lamp behavior by squaring the input voltage. In fact this block separates the modulator signal from carrier signal.

\section{Blocks 3, 4: Weighting Filters}

Block 3 contains two consecutive filters and one selector. The first filter eliminates the DC component and components with frequencies equal to double fundamental frequency. The second filter contains frequency response of the flicker-meter as compared with modulating fluctuations.

Block 4 contains a squaring multiplier and first-order low pass filter. As a result, by using the performance of blocks 2, 3 and 4, nonlinear response of human feeling to voltage fluctuations, according to the lamp-eye-brain chain shape, is simulated. The combined lamp-eye transfer function is given as,

$$
F(s)=\frac{k \omega_{1} s}{s^{2}+2 \lambda s+\omega_{1}^{2}} \frac{1+s / \omega_{2}}{\left(1+s / \omega_{3}\right)\left(1+s / \omega_{4}\right)}
$$

in which $k=1.6357, \lambda=26.184, \omega_{1}=57.034$, $\omega_{2}=18472, \omega_{3}=8.7617$ and $\omega_{4}=108.79$.

Block 5: online statistical evaluation on flicker levels

Block 5 carries out an online statistical evaluation on flicker levels. Therefore, direct calculation of the important parameters is possible. In this block, flicker signal is sampling with a constant rate. In each moment, that the flicker signal magnitude is specified, the number of corresponding counter is increased. Therefore, the frequency distribution function of the input values can be found. If the sampling frequency is chosen properly (that should be greater than the maximum flicker frequency), flicker level distribution at that time period will be determined at the end of the measurement time. The CPF of the flicker levels can be obtained from adding the number of all counters and then considering the number of each class in comparing with the obtained total value. By using these results we can obtain the cumulative probability function. By using $\mathrm{CPF}$, important statistical values such as average value, variance of the flicker level over observation time period of the flicker level for specified percent of time and increments or decrements from that prescribed levels can be obtained.

\subsection{Applying IEC Flicker Meter in Three Phase EAF before Compensation}

For obtaining instantaneous flicker sensation curve, IFL curves were evaluated for $15-\mathrm{sec}$ intervals. So that Pst value in each second is obtained by considering the IFL curve in the same instant. Finally having 15 points, instantaneous flicker sensation curve is estimated. Fig. 4 shows IFL curve and its corresponding CPF curve for $1^{\text {st }}$ Second. Fig. 5 shows the instantaneous flicker sensation curve for the phase to ground voltage of the three phase EAF before compensation. 


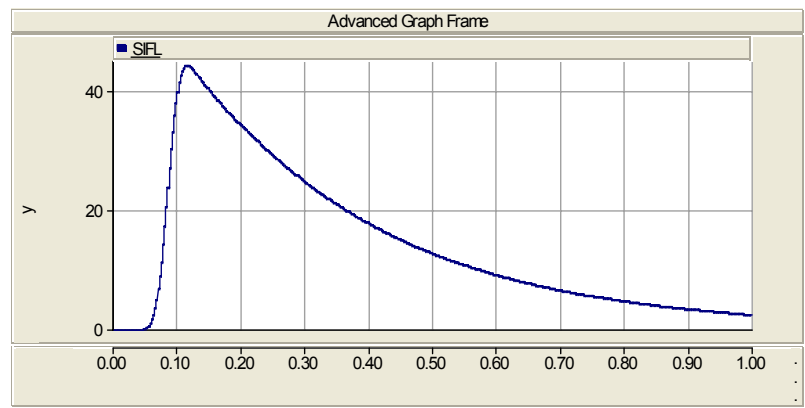

(a)

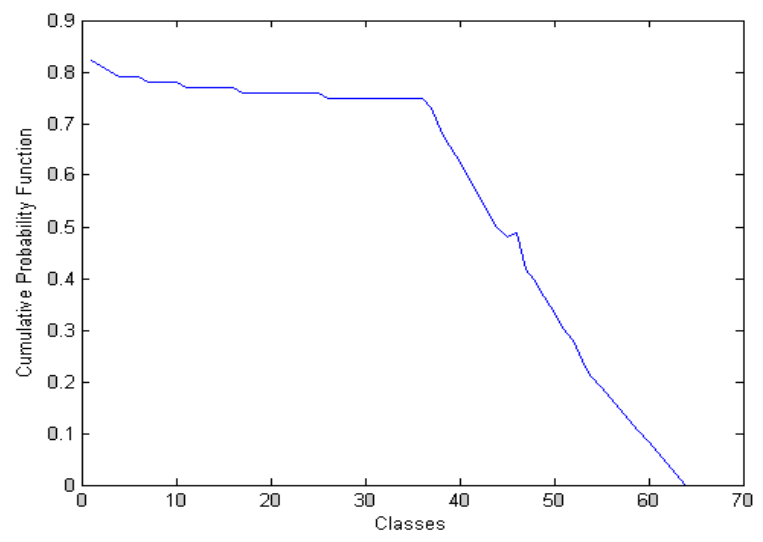

(b)

Fig. 4. IFL curve (a) and its corresponding CPF curve (b) for $1^{\text {st }}$ Second.

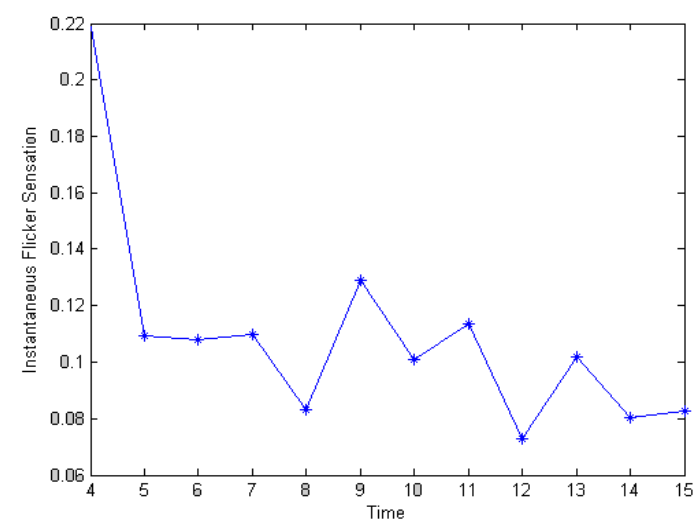

Fig. 5. Instantaneous flicker sensation curve before compensation.

\section{Closed Loop Control of the TCR/FC}

\section{Compensator using Voltage Regulator Approach}

In closed loop control of the TCR/FC compensator, a voltage error that is the difference between actual voltage and exerting reference voltage to the compensator, is measured. This error is applied for increasing or decreasing the susceptance of the compensator. In this method the response speed and stability are determined by closed-loop gain coefficient and regulating system time constants. Here, closed-loop gain coefficient is proportional to source impedance or system impedance. This means that by increasing the system impedance, compensator response speed is increased but stability of the system is decreased. Considering the nonlinear relation between voltage error and compensator current, we apply a linearizing system that is the same susceptance calculator system is applied [13]. Fig. 6 shows the compensator system block diagram using voltage regulation approach. In Fig. 6, set of linearizing blocks, firing pulse generator and variable susceptance are the same as in open loop system and parallel to their operations, determined exerting firing angle is applied to the TCR Thyristors. This means that the obtained firing angle variation is finally added to or subtracts from the open-loop system firing angle. This approach can compensate voltage flicker to some extent. Here, voltage error amplifier is applied to gradually suppress the error. Fig. 7 shows the equivalent circuit of the EAF with TCR/FC compensator. It can be seen that the power system of EAF contains harmonic filters for $2^{\text {nd }}, 3^{\text {rd }}, 4^{\text {th }}$ and $5^{\text {th }}$ order harmonics. These tuned filters are carefully designed by the authors according to the different constraints such as resonance of each filter with the whole network. It is supposed that they will approximately suppress the mentioned existing harmonics below the desired values.

In closed loop control, the firing angle difference $(\Delta \alpha)$ with respect to the open loop firing angle ( $\left.\alpha_{\text {Open-Loop }}\right)$ is calculated based on the ideas followed in Figs. 8. At first, for a fundamental reactive power demand, $\alpha_{\text {Open-Loop }}$ is estimated. Then, according to the Figs. $8 \Delta \alpha$ is evaluated. Finally, closed loop firing angle $\left(\alpha_{\text {TOT }}\right)$ is calculated.

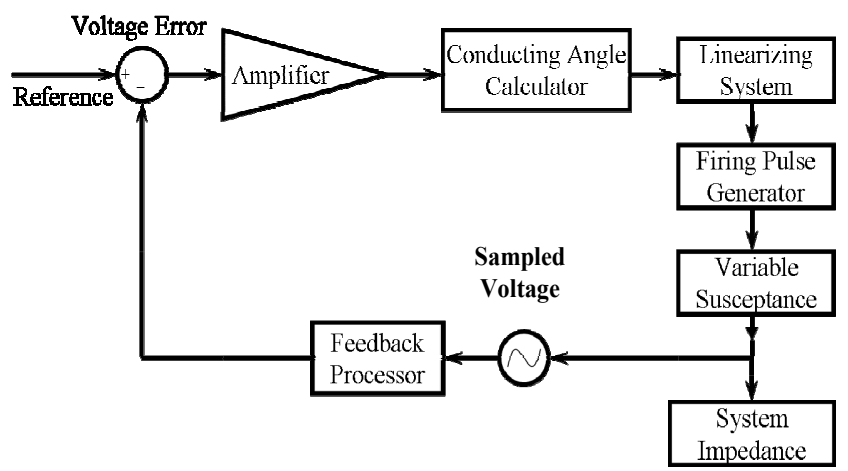

Fig. 6. Compensator block diagram based on closed loop control system using voltage regulation approach [13].

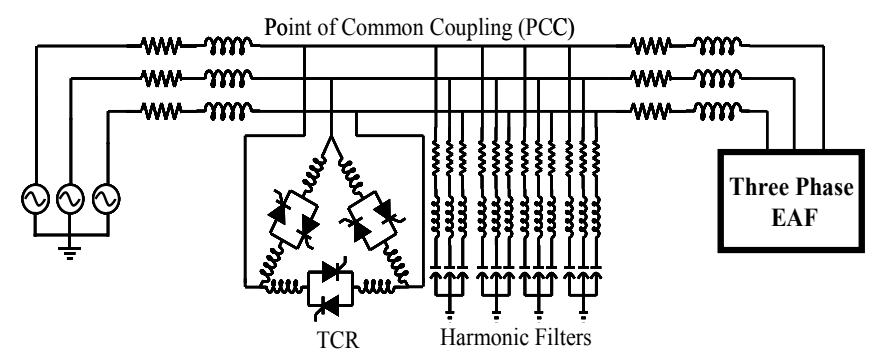

Fig. 7. The equivalent circuit of the EAF with TCR/FC compensator. 


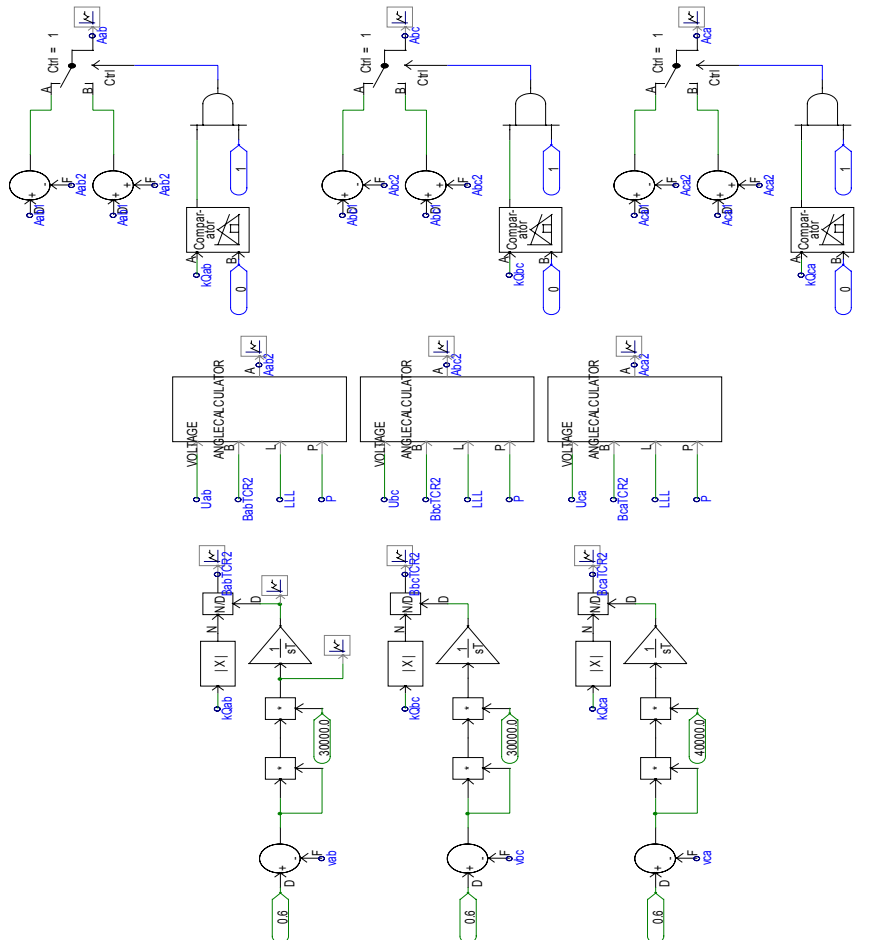

Fig. 8. $\Delta \alpha$ calculation in voltage regulation approach

Then, the compensators will try to carry out the compensation only for the fundamental component reactive power. To accomplish the prescribed method, at first line-to-line sampled voltages obtained from EAF are used to calculate consuming reactive power and susceptance. So by using the set of equations (2) [14], arc consuming reactive power and corresponding susceptances of the electric arc are obtained and, then, electric arc line-to-line voltages are obtained by dividing the value of the reactive powers to the susceptances [13],

$$
\left\{\begin{array}{l}
B_{r}^{a b}=\frac{1}{3 \sqrt{3} U^{2}} \times \frac{1}{T} \int\left[u_{b c}(t) i_{a}(t)+u_{c a}(t) i_{b}(t)-u_{a b}(t) i_{c}(t)\right] d t \\
B_{r}^{b c}=\frac{1}{3 \sqrt{3} U^{2}} \times \frac{1}{T} \int\left[-u_{b c}(t) i_{a}(t)+u_{c a}(t) i_{b}(t)+u_{a b}(t) i_{c}(t)\right] d t \\
B_{r}^{c a}=\frac{1}{3 \sqrt{3} U^{2}} \times \frac{1}{T} \int\left[u_{b c}(t) i_{a}(t)-u_{c a}(t) i_{b}(t)+u_{a b}(t) i_{c}(t)\right] d t
\end{array}\right.
$$

Where $U$ is the rms value of the phase voltage, $u_{a b}(t), u_{b c}(t)$ and $u_{c a}(t)$ are the instantaneous values of the line-to-line voltages and also $i_{a}(t), i_{b}(t)$ and $i_{c}(t)$ are the line currents. Furthermore,

$$
V_{c a}=\sqrt{\frac{Q_{c a, \text { Load }}}{B_{c a, \text { Load }}}}, \quad V_{b c}=\sqrt{\frac{Q_{b c, \text { Load }}}{B_{b c, \text { Load }}}}, \quad V_{a b}=\sqrt{\frac{Q_{a b, \text { Load }}}{B_{a b, \text { Load }}}}
$$

After obtaining sampled voltages, these voltages will be compared with reference voltages. In fact reference voltage is line-to-line voltage at PCC, whenever there are no load and compensators. Then, by using obtained voltage error and measured reactive power at PCC, the susceptance variation is measured and consequently firing angle variation is obtained. In fact, by using present reactive power at PCC and obtained voltage error, required susceptance for eliminating the error is found and in continuation, required firing angle variation to reach to this susceptance is obtained. If the measured reactive power at PCC is negative, this variation of firing angle is subtracted from the open loop control system firing angle. Because the negative value reactive power at PCC means that TCR absorbs reactive power lower than the essential value, therefore the firing angle should be decreased. On the other hand, if the measured reactive power at PCC is positive, this variation of firing angle, will add to the open loop control system firing angle. Because the positive reactive power at PCC means that TCR absorbs greater reactive power than the essential value, therefore, the firing angle should be increased [13], [15]. Equations (4) and (5) show how to exert the $\Delta \alpha$ to the firing angle obtained from open loop control system.

$$
\begin{aligned}
& \alpha_{T O T}=\alpha_{O P E N-L O O P}+\Delta \alpha \Leftrightarrow Q_{P C C \geq 0} \\
& \alpha_{T O T}=\alpha_{O P E N-L O O P}-\Delta \alpha \Leftrightarrow Q_{P C C \leq 0}
\end{aligned}
$$

\section{The Proposed Closed Loop Control of the TCR/FC Compensator using Power Factor Enhancement Approach}

One possibility in compensation is to set the total average power factor (load and compensator) and another option is to set pure compensation in zero MVAr average value. The concept of this method is that there is no compensation for the load in steady state, but for the load variation, fast compensation is exerted from the open loop control system [13]. Reactive power regulator or closed loop control system power factor regulator response speed is slower in comparison with open loop control system. In this section, closed loop control of the TCR/FC compensator, with the purpose of power factor enhancement is evaluated. In this method by calculating the firing angle variation that can make the whole power factor closer to the desired power factor, and exerting it to the firing angle that obtained from the open loop control system, the total power factor is enhanced.

\subsection{Power Factor in Polluted Systems}

In sinusoidal balanced systems, power factor is defined as the cosine of the phase angle difference between voltage and current phasors. But in polluted systems, because of voltage and current harmonic phasors, this definition can not be used [16]-[20]. In non-sinusoidal systems, to find power factor, at first, the existing harmonic components should be identified. For example, by considering the case study system in this paper, the $2^{\text {nd }}, 3^{\text {rd }}, 5^{\text {th }}$ and $7^{\text {th }}$ harmonics are taken into account. Then using proper filters, the different harmonic components will be separated from each other. 
For example for separating the fundamental component, by taking the system frequency $(50 \mathrm{~Hz})$ into account, we should pass the signal from the low pass filter with a cutoff frequency equal to $80 \mathrm{~Hz}$. In the same manner, the other harmonic components are separable. At the next step, by using the set of Equation (6) and fundamental components of voltages and currents, positive, negative and zero sequence components of fundamental voltage and current signals can be obtained [18], [21], [22]. Fig. 9 shows the simulated block diagram based on the set of Equation (6):

$$
\begin{aligned}
& u_{1}^{+}(t)=\frac{1}{3}\left\{u_{a 1}(t)+u_{b 1}\left(t-\frac{2}{3} T\right)+u_{c 1}\left(t-\frac{1}{3} T\right)\right\} \\
& u_{1}^{-}(t)=\frac{1}{3}\left\{u_{a 1}(t)+u_{b 1}\left(t-\frac{1}{3} T\right)+u_{c 1}\left(t-\frac{2}{3} T\right)\right\} \\
& u_{1}^{0}(t)=\frac{1}{3}\left\{u_{a 1}(t)+u_{b 1}(t)+u_{c 1}(t)\right\}
\end{aligned}
$$

where In the following equation, $u_{a l}(t), u_{b l}(t)$ and $u_{c l}(t)$ are the fundamental components of the phase voltages obtained through filtering the phase voltage signals and also $u_{1}^{+}(t), u_{1}^{-}(t)$ and $u_{1}^{0}(t)$ are positive, negative and zero sequence components of fundamental phase voltages respectively. Corresponding parameters for line currents and line-to-line voltages can be calculated in the same manner. Then, using the RMS value of positive sequence component, active power $\left(P_{1}^{+}\right)$is obtained as follows:

$$
P_{1}^{+}=3 V_{1}^{+} I_{1}^{+} \operatorname{COS} \phi_{1}^{+}
$$

where $V_{1}^{+}$and $I_{1}^{+}$are the rms value of the positive sequence component of fundamental component of the phase voltage and line current, respectively. $\phi_{1}^{+}$is also the phase difference between $V_{1}^{+}$and $I_{1}^{+}$.

Total apparent power, considering all harmonic components, can also be obtained as follows:

$$
S_{e}=3 V_{e} I_{e}
$$

in which,

$$
\begin{gathered}
V_{e}=\sqrt{\left(V_{e 1}^{2}+V_{e 2}^{2}+V_{e 3}^{2}+V_{e 5}^{2}+V_{e 7}^{2}\right)} \\
I_{e}=\sqrt{\left(I_{e 1}^{2}+I_{e 2}^{2}+I_{e 3}^{2}+I_{e 5}^{2}+I_{e 7}^{2}\right)}
\end{gathered}
$$

In Equations (8) and (9), $V_{e 1}$ and $I_{e 1}$ values are calculated from Equations (11) and (12) respectively. The other components are calculated in the same way.

$$
V_{e 1}=\sqrt{\left(\frac{V_{a 1}^{2}+V_{b 1}^{2}+V_{c 1}^{2}}{6}+\frac{V_{a b 1}^{2}+V_{b c 1}^{2}+V_{c a 1}^{2}}{18}\right)}
$$

$$
I_{e 1}=\sqrt{\frac{I_{a 1}^{2}+I_{b 1}^{2}+I_{c 1}^{2}}{3}}
$$

Finally, power factor can be defined according to the Equation (13) in polluted and unbalanced environments [18], [21], [22].

$$
P F=\frac{P_{1}^{+}}{S_{e}}
$$

By accomplishing above process, the simulated power factor at PCC is shown in Fig. 10.

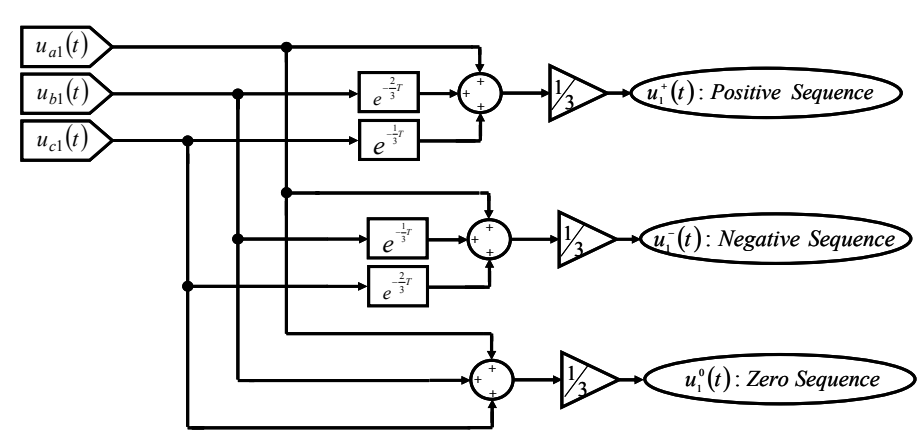

Fig. 9. Block diagram of set of Equation (6).

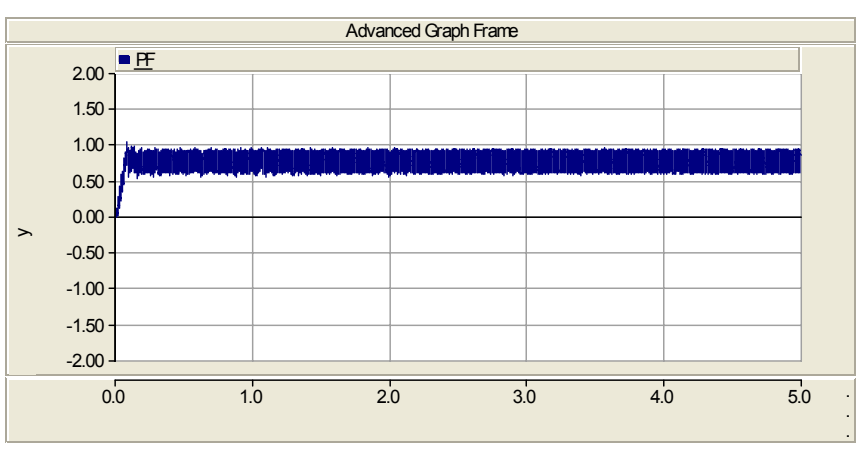

Fig. 10. Obtained waveform for power factor.

\subsection{Closed Loop Control of the Compensator using Power Factor Enhancement Approach}

In this section, at first, the actual power factor at PCC is obtained and then it is compared with the desired power factor. At the next step, by varying the TCR firing angle, we cause actual power factor to be close to the desired one. With acceptable approximation, it can be seen that measured power factor at PCC, is arisen from phase difference between fundamental component of arc voltage and current, fundamental component of filter voltage and current and TCR voltage and current. In this approximation, the harmonic effects in calculation of the phase difference between voltage and current of the arc and filters are neglected. But this simplification is not applied to TCR. We suppose that the total phase difference between TCR voltage and current by considering the harmonic effects is $\beta$. Phase difference between arc voltage and current fundamental components 
depends on system nature and we can not vary it. But we can vary the phase difference between TCR voltage and current by changing the switching strategies. Therefore, by setting the TCR switching pattern, we can make actual power factor close to the desired one. For this purpose, we will obtain $\beta$ in two states. At the first state, $\beta$ is obtained from the actual measured power factor and at the second state, $\beta$ is obtained from the desired reference power factor, respectively. The difference in these two states is calculated and exerted on TCR firing angle. In fact, by applying this approach, $\beta$ reaches to the desired $\beta$. Consequently, power factor enhancement is expected. Assuming that the phase difference between arc voltage and current fundamental component is $\phi_{1}^{+}$and the one for the filter is $\delta_{1}^{+}$, then, Equation (14) can be written approximately as follows:

$$
P F \approx \operatorname{Cos}\left(\beta+\phi_{1}^{+}+\delta_{1}^{+}\right)
$$

Consequently $\beta$ angle can be obtained from Equation (15):

$$
\beta \approx \operatorname{Cos}^{-1}(P F)-\phi_{1}^{+}-\delta_{1}^{+}
$$

It can be proved that $\beta$ is approximately equal to $90^{\circ}$, if voltage of each phase of the TCR is considered to have sinusoidal form. The instantaneous waveform of current of the TCR, is shown in Fig. 11. By applying Fourier series to the current waveform, according to Equation (16) only cosine terms are appeared. Consequently the phase difference is approximately equal to $90^{\circ}$.

$$
i(t)=\sum_{n=1,3,5, \ldots}^{\infty} a_{n} \operatorname{Cos} n \omega t
$$

In continuation, for each phase, $\beta$ is calculated separately for two different conditions. One is actual measured power factor and another one is desired reference power factor. By using the difference of the $\beta$ in these two states and passing $\Delta \beta$ through a PI controller, $\Delta \alpha$ value can be obtained for each phase of the TCR. After obtaining $\Delta \alpha$, because of its variation over one period,

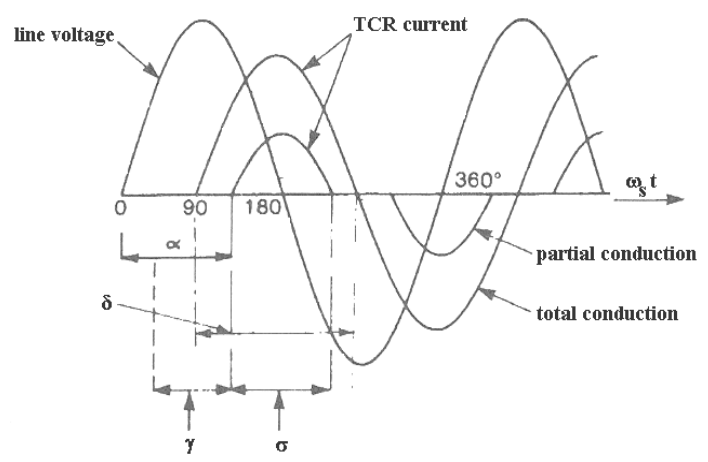

Fig. 11. TCR instantaneous current waveform. we sample $\Delta \alpha$ at starting point of each cycle and this sample is $\Delta \alpha$ value over that cycle. Obtained $\Delta \alpha$ is added to the firing angle that is obtained from open loop control system, in each cycle. By using actual power factor and reference power factor equal to $0.9, \Delta \beta$ value is obtained and then we can reach to $\Delta \alpha$ and exert it to open loop firing angle. Fig. 12 represents the mechanism of calculating $\Delta \alpha$. It can be seen in Fig. 13 that power factor is improved after exerting $\Delta \alpha$, i.e., closed loop control based on controlling power factor.

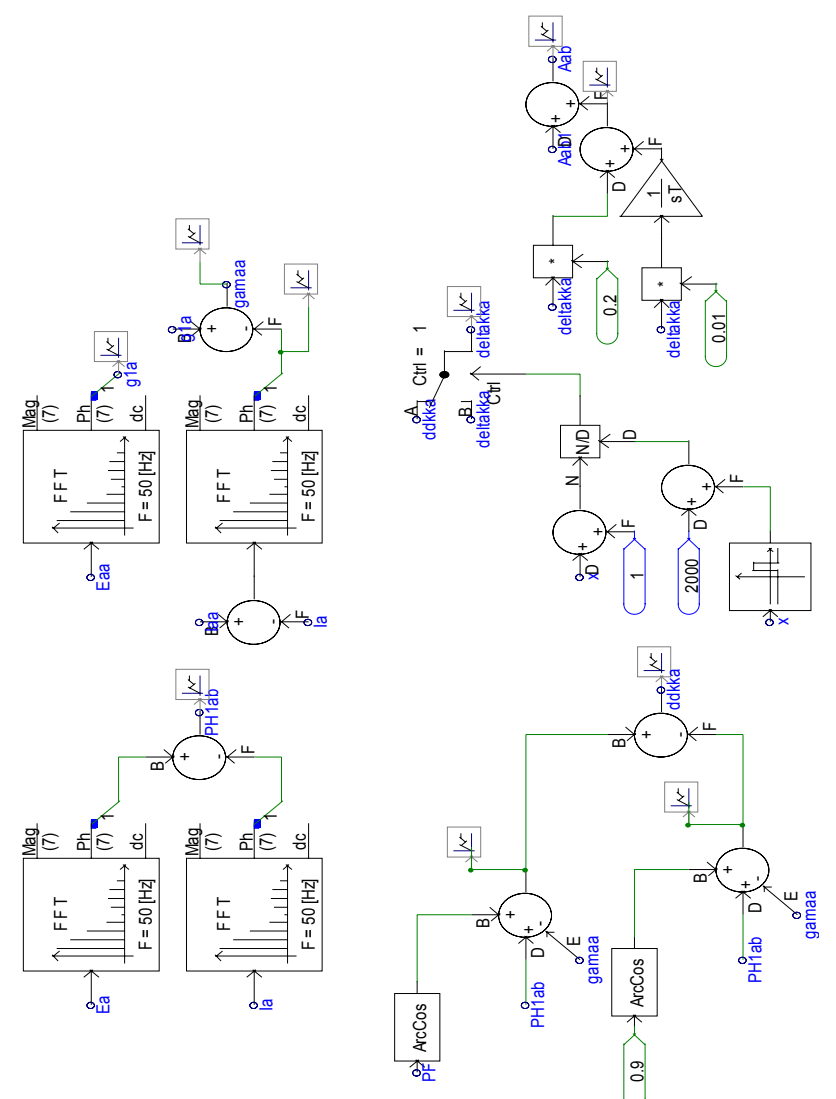

Fig. 12. $\Delta \alpha$ calculation in power factor enhancement approach.

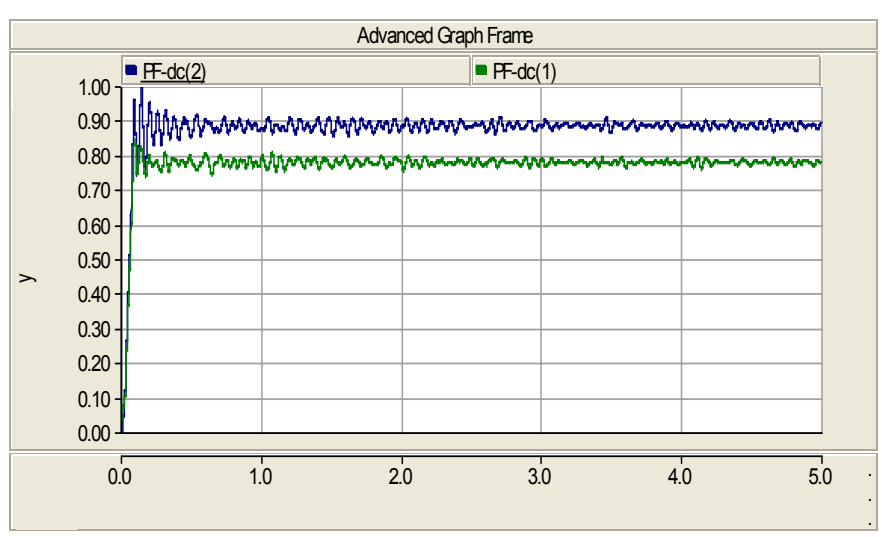

Fig. 13. Comparison the power factor average value before (lower curve) and after (upper curve) exerting $\Delta \alpha$. 


\section{Applying a Predictive Method in Closed Loop Control of TCR/FC Compensator}

The ability of the static VAr compensator (SVC) to mitigate the flicker intensity depends on its reaction speed. The speed of these compensators is limited by delay in measurements of the Thyristors firing angle circuits. In this paper, by applying a predictive method to compensate the delay time, enhancement of the compensator performance is achieved. In this method by using the previous values of the load reactive power, its future values are predicted. Maximum delay in Thyristor ignition is half cycle of line frequency. Due to this inherent delay, the compensator ability to reduce flicker intensity depends on the frequency of reactive power variations. With the load variation frequencies of up to almost $6 \mathrm{~Hz}$, compensator performance is very good. But at variations with higher frequencies, SVC can not compensate the load effectively. In this paper by applying a predictive method to compensate the delay time, we improve the SVC performance in flicker reduction [23].

\subsection{Improving Compensator Performance with Esti- mating Load Reactive Power in Future Times [23]}

To reduce the negative effects of the time delay, we try to estimate the load reactive power in future times. Predicted values are used to compensate the delay time as a reference for static compensator. Reactive power estimation is accomplished using previous sample values of the reactive power. The Laplace transform of the lead time $\mathrm{T}$ prediction function can be written as,

$$
e^{S T} \cong \sum_{n=0}^{M} k_{n} e^{-n S T_{1}}
$$

The optimum coefficients are found by minimizing the following error function [23],

$$
F=\int_{\omega_{1} T}^{\omega_{2} T}\left|e^{j \omega T}-\sum_{n=0}^{M} k_{n} e^{-j n \omega T_{1}}\right|^{2} d \omega T
$$

In which $\omega_{1}$ and $\omega_{2}$ values depend on compensation frequency range. They are chosen in a manner that the frequency of the signal that we want to shift it to the left in time domain, should locate between them. Therefore, the following set of equations needs to be solved to find the optimum coefficients [23].

$$
\frac{\partial F}{\partial k_{0}}=0, \frac{\partial F}{\partial k_{1}}=0, \ldots, \frac{\partial F}{\partial k_{M}}=0 .
$$

Table 1 shows obtained coefficients for the signal with frequency equal to $50 \mathrm{~Hz}$ and $T=10 \mathrm{~ms}, T_{1}=14 \mathrm{~ms}$ and $M=3$.
Table 1. Optimum coefficients for voltage and current prediction

\begin{tabular}{c|c|c}
\hline & $\mathrm{X}_{1}=2.2$ & $\mathrm{X}_{1}=2.51$ \\
& $\mathrm{X}_{2}=4.08$ & $\mathrm{X}_{2}=3.77$ \\
\hline $\mathrm{K}_{0}$ & -1.2691 & -1.1270 \\
\hline $\mathrm{K}_{1}$ & -0.1118 & -0.1692 \\
\hline $\mathrm{K}_{2}$ & -0.2740 & -0.3129 \\
\hline $\mathrm{K}_{3}$ & 0.0976 & 0.0368 \\
\hline
\end{tabular}

\subsection{Creation of the Predictive Block}

Considering the $K_{n}$ optimum values that obtained in the last part, we can design the predictive block according to Fig. 14. We can change the measure of shifting to the left, depending on our requirement by setting the values of $r$ and $T_{1}$ parameter s. But in this paper, because of the half cycle time delay in TCR control, the best value for shifting to the left is one half-cycle. It is notable that full conduction is achieved with a firing angle of $90^{\circ}$ and partial conduction is obtained with firing angles between $90^{\circ}$ and approximately $180^{\circ}$ (Fig. 15) [15].

Now, using predictive block, all of the signals that interfere on determining the Thyristors firing angles, are shifted to the left for one half cycle. Consequently, by considering the delay time compensation in reactive power provided, we can expect flicker intensity mitigation.

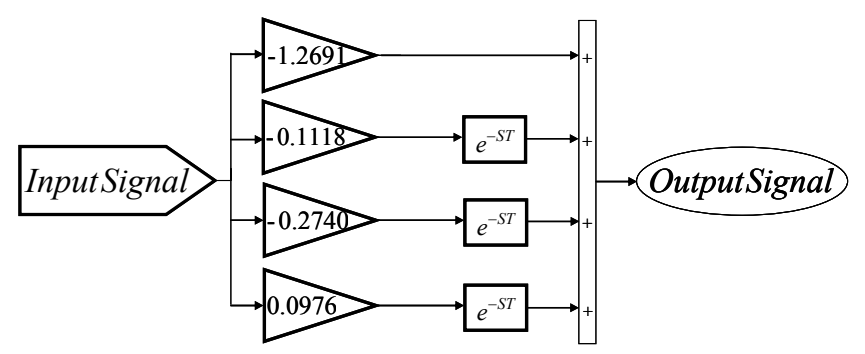

Fig. 14. Predictive block.

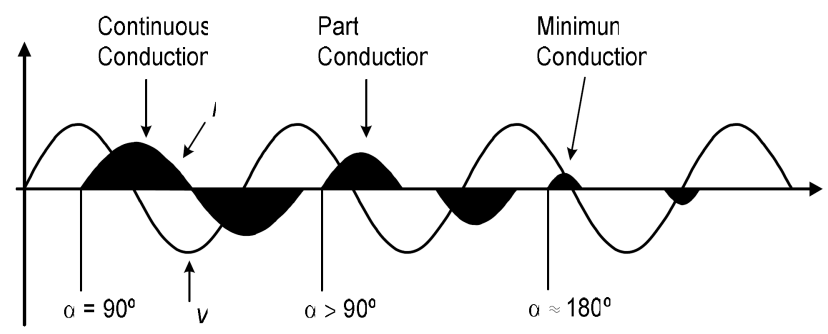

Fig. 15. Voltage and current waveforms in a TCR for different Thyristor firing angle, $\alpha$ [14].

\section{Applying IEC Flicker-meter After Closed Loop Compensation Method using Voltage Regulation Approach}

After closed loop control of the TCR/FC compensator, using voltage regulation approach, voltage flicker at PCC 
should be evaluated. So by applying IEC flicker meter, instantaneous flicker sensation curve is obtained and is compared with the previous one, i.e., before compensation. Fig. 16 shows instantaneous flicker sensation curves before and after closed loop compensation using voltage regulation approach. Fig. 17 shows the IFL curve and its corresponding CPF curve for $1^{\text {st }}$ second after applying closed loop control. By comparing these two curves, we can observe that closed loop method at some points reduces flicker intensity and in a few points increases that.

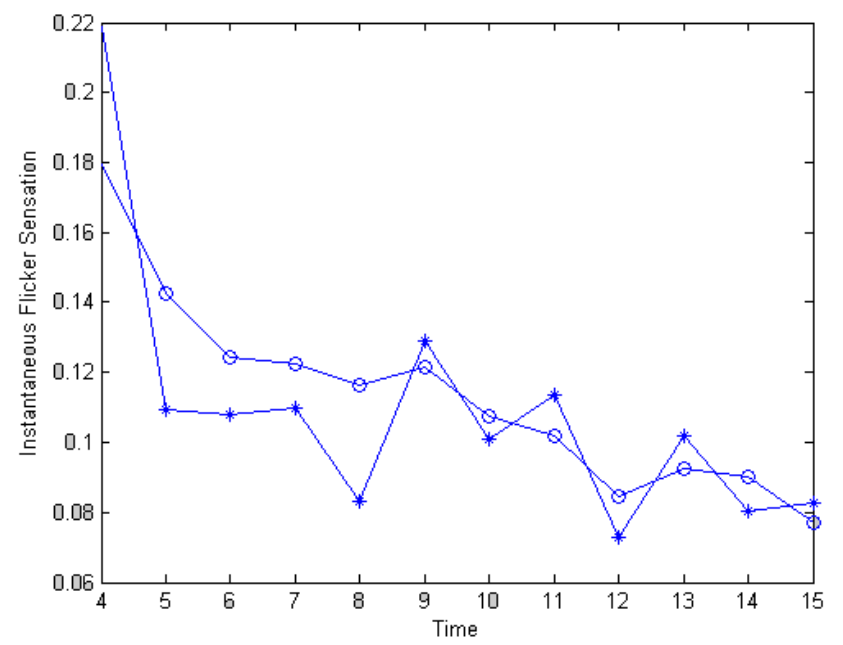

Fig. 16. Instantaneous flicker sensation curve before and after closed loop compensation using voltage regulation approach.

\section{Applying IEC Flicker-meter after Exerting Predictive Method on Closed Loop Control Method using Voltage Regulation Approach}

After exerting predictive method on closed loop control method, using voltage regulation approach, voltage flicker intensity at PCC was evaluated. Then by applying IEC flicker meter, according to the previous case, instantaneous flicker sensation curve is obtained. This curve is compared with the obtained one before compensation and after closed loop compensation using voltage regulation approach. Fig. 18 shows instantaneous flicker sensation curve after applying predictive method on closed loop control method using voltage regulation approach. Fig. 19 shows a comparison between the results of three strategies, 1 is dedicated to before compensation case, case 2 is the obtained curve after closed loop compensation using voltage regulation approach and the last one, case 3, is the obtained curve after exerting predictive method on closed loop compensation using voltage regulation approach. Furthermore, the Pst values related to Fig. 19 are given in Table 2 from $\mathrm{t}=1 \mathrm{sec}$ to $\mathrm{t}=5 \mathrm{sec}$. We find that flicker intensity is decreased perceptibly by using predictive method. Fig. 20 shows the IFL curve and its corresponding CPF curve for $1^{\text {st }}$ second, after applying predictive method.

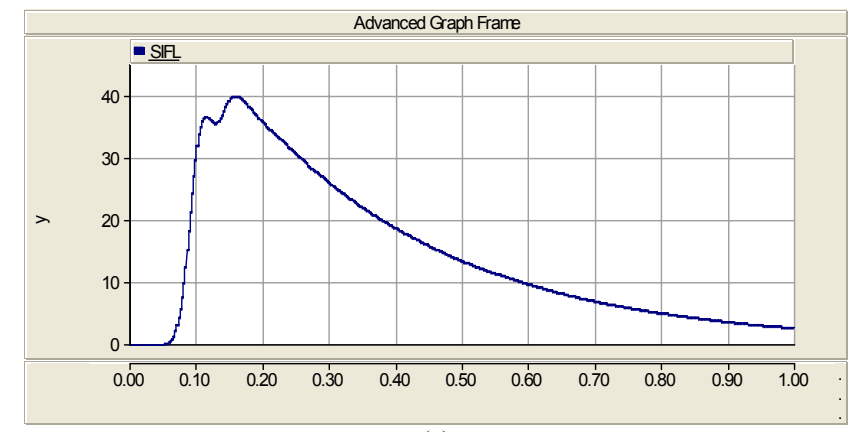

(a)

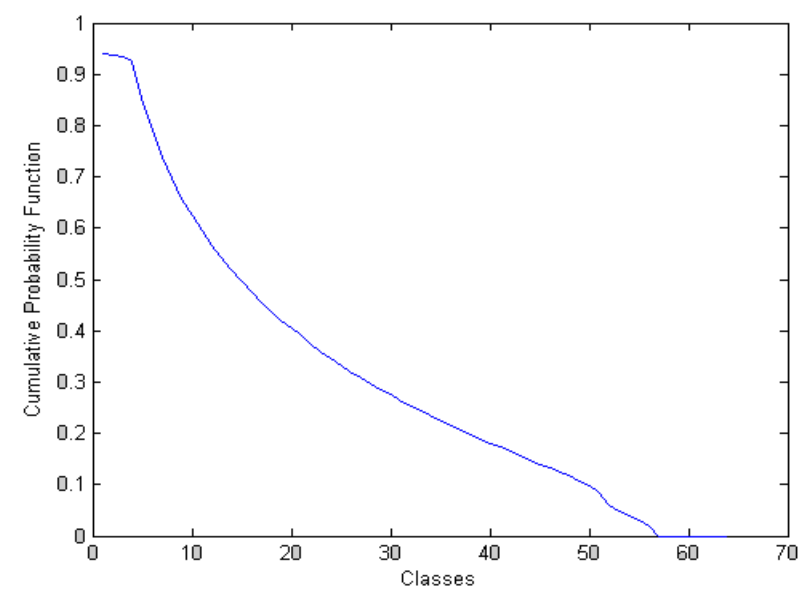

(b)

Fig. 17. IFL curve (a) and its corresponding CPF curve (b) for $1^{\text {st }}$ second after applying closed loop control.

Table 2. Pst values concern to Fig. 20. from $t=1 \mathrm{sec}$ to $t=5 \mathrm{sec}$

\begin{tabular}{c|c|c|c}
\hline Time & $\begin{array}{c}\text { Pst value of } \\
\text { curve (1) }\end{array}$ & $\begin{array}{c}\text { Pst value of } \\
\text { curve (2) }\end{array}$ & $\begin{array}{c}\text { Pst value of } \\
\text { curve (3) }\end{array}$ \\
\hline $\mathrm{t}=1 \mathrm{Sec}$ & 4.5593 & 4.0649 & 3.1133 \\
\hline $\mathrm{t}=2 \mathrm{Sec}$ & 0.9723 & 1.0069 & 0.7764 \\
\hline $\mathrm{t}=3 \mathrm{Sec}$ & 0.3466 & 0.2683 & 0.2373 \\
\hline $\mathrm{t}=4 \mathrm{Sec}$ & 0.2190 & 0.1794 & 0.1588 \\
\hline $\mathrm{t}=5 \mathrm{Sec}$ & 0.1093 & 0.1428 & 0.1385 \\
\hline
\end{tabular}

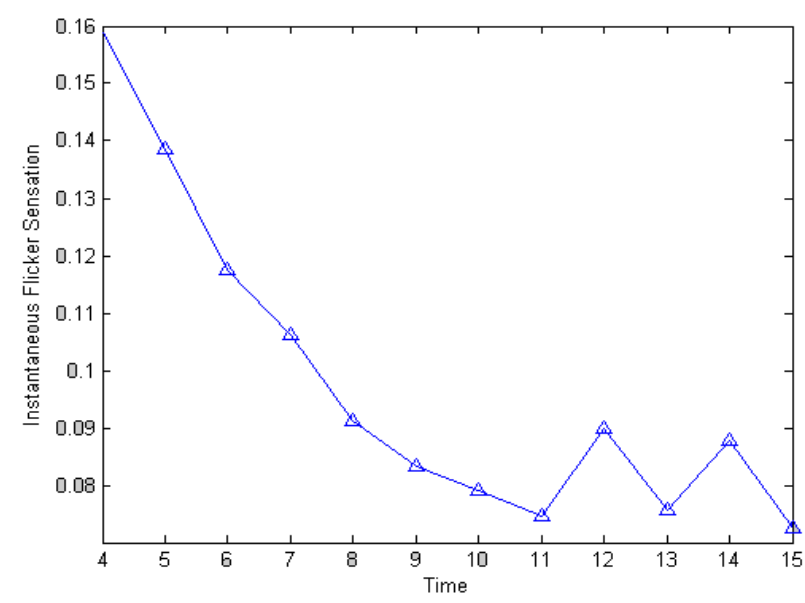

Fig. 18. Instantaneous flicker sensation curve after applying predictive method on closed loop control method using voltage regulation approach. 


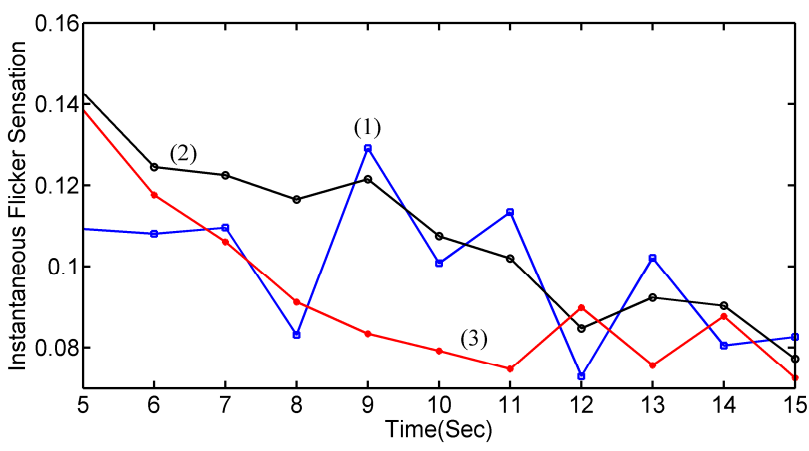

Fig. 19. A comparison between obtained curves in three strategies.

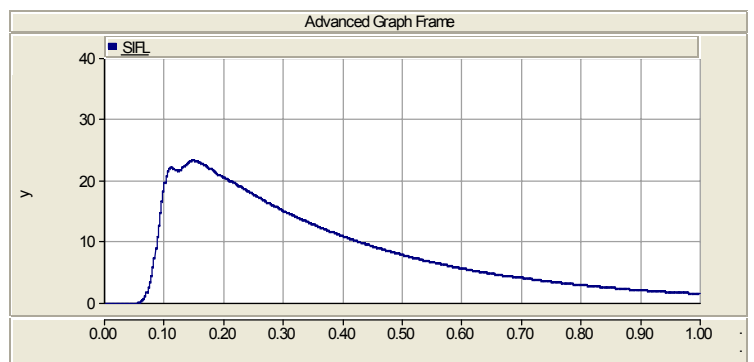

(a)

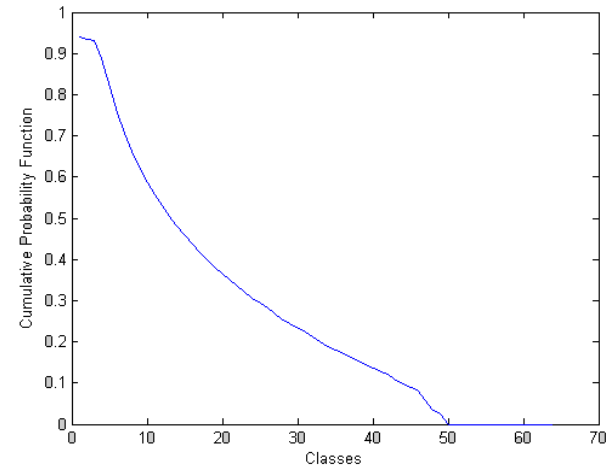

(b)

Fig. 20. IFL curve and its corresponding CPF curve for $1^{\text {st }}$ second, after applying predictive method.

\section{Exerting Predictive Method on Closed Loop Control Method using Power Factor Enhancement Approach}

In previous section, predictive method was applied with closed loop control method using voltage regulation approach and the result is that flicker intensity at PCC is decreased perceptibly. In this section, the result of applying predictive method on closed loop control strategy using power factor enhancement approach is shown in Figs. 21 and 22. These Figs. show instantaneous flicker sensation curves before compensation, after exerting predictive method on closed loop compensation using voltage regulation approach and after applying predictive method on closed loop compensation using power factor enhancement approach. Furthermore, the Pst values related to Fig. 22 are given in Table 3 from $\mathrm{t}=1 \mathrm{sec}$ to $\mathrm{t}=5 \mathrm{sec}$. The simulations were also carried out for 1 Min. Simulation and their running time were more than 40 hours for this 1-minute time duration (Appendix I).

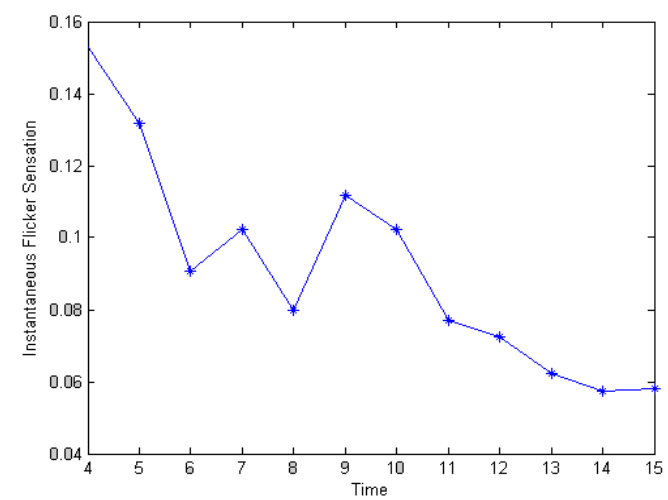

Fig. 21. Instantaneous flicker sensation curve after applying predictive method on closed loop control method using power factor enhancement approach.

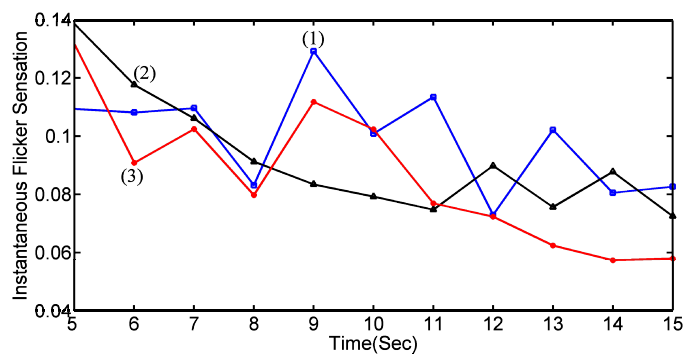

Fig. 22. Instantaneous flicker sensation curves before compensation (1), after exerting predictive method on closed loop compensation using voltage regulation approach (2) and after applying predictive method on closed loop compensation using power factor enhancement approach (3).

Table 3. Pst values concern to Fig. 23 . from $t=1 \mathrm{sec}$ to $t=5 \mathrm{sec}$

\begin{tabular}{c|c|c|c}
\hline Time & $\begin{array}{c}\text { Pst value of } \\
\text { curve (1) }\end{array}$ & $\begin{array}{c}\text { Pst value of } \\
\text { curve (2) }\end{array}$ & $\begin{array}{c}\text { Pst value of } \\
\text { curve (3) }\end{array}$ \\
\hline $\mathrm{t}=1 \mathrm{Sec}$ & 4.5593 & 3.1133 & 2.0744 \\
\hline $\mathrm{t}=2 \mathrm{Sec}$ & 0.9723 & 0.7764 & 0.5841 \\
\hline $\mathrm{t}=3 \mathrm{Sec}$ & 0.3466 & 0.2373 & 0.2440 \\
\hline $\mathrm{t}=4 \mathrm{Sec}$ & 0.2190 & 0.1588 & 0.1528 \\
\hline $\mathrm{t}=5 \mathrm{Sec}$ & 0.1093 & 0.1385 & 0.1316 \\
\hline
\end{tabular}

\section{Conclusion}

Arc model in this paper is derived from sampling arc currents and their corresponding voltages. Then modulating the arc voltage is considered by a band-limited white noise. This model can represent an actual arc characteristic. Among different methods in measurement of fundamental component of reactive power in polluted and unbalanced systems, it is shown that one of the best methods for reactive power measurement in these systems is its instantaneous measurement. In this paper, a proposed method for TCR/ FC closed 
loop control is suggested. This proposed method is based on applying a predictive method with closed loop control of the compensator that can desirably suppress the flicker intensity. This closed loop control is accomplished based on both PCC voltage regulation and power factor corrections.

\section{Appendix 1: Pst (short-term flicker indication) Curve before and after Applying Predictive Method}

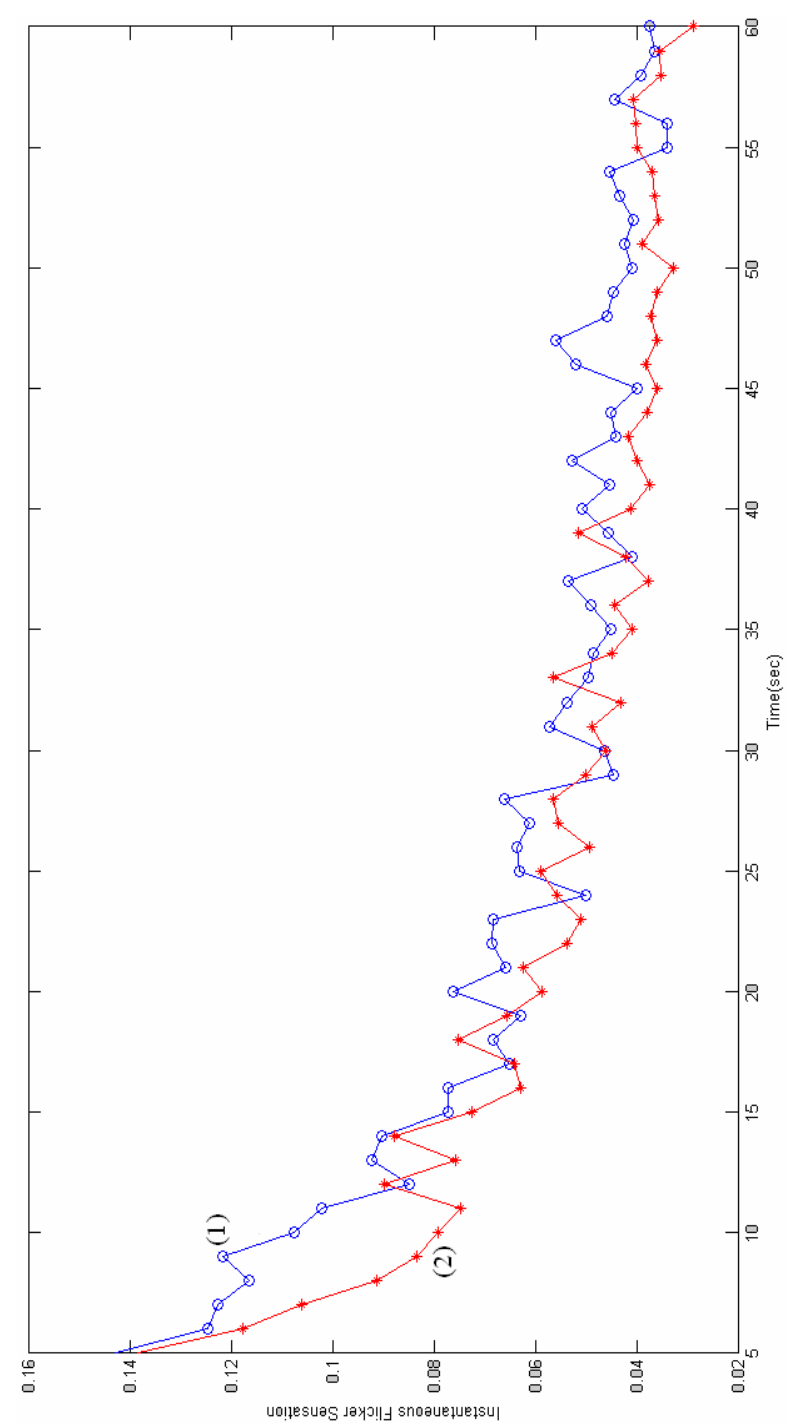

Fig, App. 1 Instantaneous flicker sensation curve before applying predictive Method (1) and after that (2) on closed loop control method using voltage regulation approach. ( the simulations are carried out for 60 seconds and it is notable that the whole simulation run time was about 40 hours for each curve.)

\section{Acknowledgements}

Special thanks are dedicated to the center of research and technology, at the University of Isfahan for their full supports. The present research work was originally related to a research project, which was successfully carried out and finalized by the authors. Special thanks go to the people of Mobarakeh Steel-Making Complex for their full support to us. We are very grateful to them, and in particular, Mr. Eng. Banaeeyan, Mr. Eng. Roozafzay, Mr. Eng. Shojaea-zadeh and Mr. Eng. Nilli. At last, unless the helpful and permanent considerations of many people had been, the present work would not have been accomplished and finalized. We would really like to appreciate all of them.

Special thanks also go to the staff of the Alexander von Humboldt Foundation, for their full support to the first author. The first author participated in the Advanced Finite Element and Electromagnetic courses when he was a PostDoctoral research fellow of the Alexander von Humboldt Foundation under the supervision of Professor Rolf Hanitsch, at the Institute of Electrical Machines and Renewable Energies, at Technical University of Berlin (TUBerlin). This participation improved the knowledge of the first author about the Finite Element Method and its applications in Electromagnetics.

Valuable comments from the anonymous reviewers indeed helped to significantly improve and enhance the contents of this research. We would really appreciate their comprehensive attentions and vital considerations.

\section{References}

[1] J. Jatskevich, O. Wasynczuk, L. Conrad, "A Method of Evaluating Flicker and Flicker-Reduction Strategies in Power System," IEEE Trans. Power Del., Vol. 13, No.4, Oct., 1998.

[2] A. Garcia-Cerrada, P. Garcia-Gonzalez, R. Collantes, T. Gomez, J. Anzola, "Comparsion of ThyristorControlled Reactors and Voltage-Source Inverters for Compensation of Flicker Caused by Arc Furnaces," IEEE Trans. Power Del., Vol.15, No.4, Oct., 2000.

[3] Araceli Hernandez, Julio G. Mayordomo, Rafael Asensi, Luis F. Beites, "A New Frequency Domain Approach for Flicker Evaluation of Arc Furnace," IEEE Trans. Power Del., Vol.18, No.2, pp.631-638, Apr., 2003.

[4] Steffen Prinz, Hermann Pietzsch, H. Kleinknecht Gmbh, "Optimal Control of Static VAr Compensators in Power Supply System with Electrical Arc Furnace," ISBN: 90-75815-08-5, EPE 2005-Dresden.

[5] Srinivas Varadan, Elham B. Makram, Adly A. Girgis, "A New Time Domain Voltage Source Model for an Arc Furnace Using EMTP,” IEEE Trans. Power Del., Vol.11, No.3, pp.1685-1691, Jul., 1996.

[6] J. J. Gutierrez, J. Ruiz, S. Ruiz de Gauna, "Linearity of the IEC Flickermeter Regarding Amplitude Variations of Rectangular Fluctuations," IEEE Trans. Power Del., Vol. 22, No.1, pp.729-731, Jan., 2007.

[7] Jin-Lung Guan, Jyh-Cherng Gu, Chi-Jui Wu, "A Novel Method for Estimating Voltage Flicker," IEEE 
Trans. Power Del., Vol.20, No.1, pp.242-247, Jan., 2005.

[8] O. Ozgun, A. Abur, "Flicker Study Using a Novel Arc Furnace Model," IEEE Trans. Power Del., Vol.17, No. 4, pp.1158-1163, Oct., 2002.

[9] Chau-Shing Wang, Michael J. Devaney, "Incandescent Lamp Flicker Mitigation and Measurement," IEEE Transaction on Instrumentation and Measurement, Vol.53, No.4, pp.1028-1034, Aug., 2004.

[10] J. Jatskevich, O. Wasynczuk, L. Conrad, "A Method of Evaluating Flicker and Flicker-Reduction Strategies in Power Systems," IEEE Trans. Power Del., Vol. 13, No.4, pp.1481-1487, Oct., 1998.

[11] G. Wiczynski, "Simple Model of Flickermeter Signal Chain for Deformed Modulating Signals", IEEE Transactions on Power Delivery, Vol. 23, No. 4, October 2008.

[12] A. Hernandez, Julio G. Mayordomo, Rafael Asensi, Luis F. Beites, "A Method Based on Interharmonics for Flicker Propagation Applied to Arc Furnaces," IEEE Trans. Power Del., Vol.20, No.3, pp.2334-3442, Jul., 2005.

[13] T. J. E. Miller, Reactive Power Control in Electrical Systems. New York: Wiley, 1982.

[14] Fei-feng Ji, Muhammad Mansoor Khan, Chen Chen, "Static Var Compensator Based on Rolling Synchronous Symmetrical Component Method for Unbalance Three-Phase System," Under Project "Power System Dynamic Analysis with Power Electronic Equipment" (No. 20030248043)., pp.621-626, 2005.

[15] J. Dixon, L. Moran, J. Rodriguez, R. Domke, "Reactive Power Compensation Technologies, State-of-theArt Review," Invited Paper.

[16] M. Cao, P. P. Biringer, "Minimizing the Three-Phase Unbalance in an Electric Arc Furnace," IEEE Transaction on Magnetics, Vol.25, No.4, pp.2849-2851, Jul., 1989.

[17] L. Cristaldi, A. Ferrero, G. Superti-Furga, "Current Decomposition in Asymmetrical, Unbalanced ThreePhase Systems Under Nonsinusoidal Conditions," IEEE Transactions on Instrumentation and Measurement, Vol.43, No.1, pp.63-68, Feb., 1994.

[18] A. Ferrero, G. Superti-Furga, "A new Approach to the Definition of Power Components in Three Phase Systems Under Nonsinusoidal Conditions," IEEE Transaction on Instrumentation and Measurement, Vol.40, No. 3, pp.568-577, Jun., 1991.

[19] Leszek S. Czarnecki, "Reactive and Unbalanced Currents Compensation in Three-Phase Asymmetrical Circuits under Nonsinusoidal Conditions," IEEE Transaction on Instrumentation and Measurement, Vol.38, No.3, pp.754-759, Jun., 1989.

[20] B. Lin, Y. Lee, "Three-phase Power Quality Compensator Under the Unbalanced Source and Nonlinear Loads," IEEE Transaction on Industrial Electronics, Vol.51, No.5, pp.1009-1017, Oct., 2004.

[21] Mahesh K. Mishra, Arindom Ghosh, Avinash Joshi,
Hiralal M. Suryawanshi, "A Novel Method of Load Compensation Under Unbalanced and Distorted Voltages," IEEE Trans. Power Del., Vol.22, No.1, pp.288-295, Jan., 2007.

[22] Patrico Salmeron, Reyes S. Herrera, "Distorted and Unbalanced Systems Compensation Within Instantaneous Reactive Power Framework," IEEE Trans. Power Del., Vol.21, No.3, pp.1655-1662, Jul., 2006.

[23] H. Samet, M. Parniani, "Predictive Method for Improving SVC Speed in Electric Arc Furnace Compensation," IEEE Trans. Power Del., Vol.22, No.1, pp. 732-734, Jan., 2007.

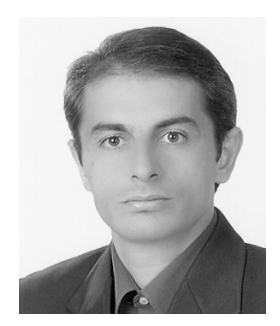

Arash Kiyoumarsi He was born in Shahr-e-Kord, Iran, on September 11th, in the year 1972. He received B.Sc. (with honors) from Petruliom University of Technology (PUT), Iran, in electronic engineering in 1995 and M.Sc. from Isfahan University of Technology (IUT), Iran, in electrical power engineering in 1998. He received Ph.D. degree from the same university in electrical power engineering in 2004. In March 2005 he jointed the faculty of University of Isfahan, Department of Electrical Engineering as an assistant professor. He was a Post-Doc. research fellow of the Alexander von Humboldt foundation at the Institute of Electrical Machines, Technical University of Berlin from February to October 2006 and July to August 2007. His research interests have included application of finite element analysis in electromagnetics, interior permanent-magnet synchronous motor drives, shape design optimization and nonlinear control of electrical machines.

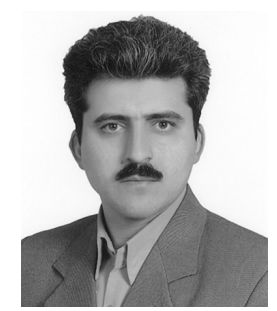

Mohammad Ataei He received the B.S. degree from the Isfahan University of Technology, Iran, in 1994, the M.S. degree from the Iran University of Science \& Technology, Iran, in 1997, and $\mathrm{PhD}$ degree from K.N. Toosi University of Technology, Iran, in 2004 (joint project with the University of Bremen, Germany) all in Electrical Engineering. Since 2004, he is with the Department of Electrical Engineering at the University of Isfahan, Iran. He has worked on time series analysis of chaotic systems and robust control. His main areas of research interest are also modeling of systems, and tracking systems. 


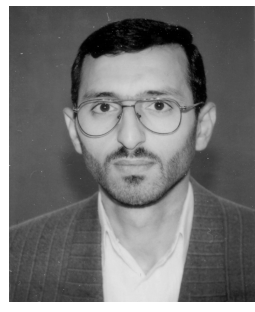

Rahmat-Allah Hooshmand He received the BSEE degree from the University of Mashhad in 1989, the MSEE from the University of Tehran/Iran and $\mathrm{PhD}$ degree from Tarbiat Modarres University/Iran in 1990 and 1995, respectively all in Electrical Engineering. Since 1995, he is with the Department of Electrical Engineering at the University of Isfahan/Iran. His main areas of research interest are modeling of Power Systems and Distribution Networks.

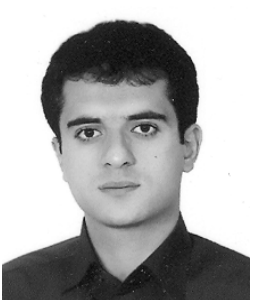

Arash Dehestani Kolagar He received B.Sc. degree from the University of Tehran in 2004, M.Sc. from the University of Isfahan, Iran in 2007, respectively all in Electrical Power Engineering. Since 2008, he is with the Department of Electrical Engineering at the Iran University of Technology and Science, Tehran, Iran as a PhD student of power engineering. His main areas of research interest are modeling of power systems and three phase electric arc furnaces. 